\title{
Eugênio Gudin
}

\author{
RICARDO BIELSCHOWSKX
}

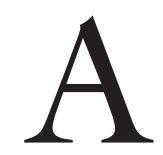

CORRENTE neoliberal foi, juntamente com a desenvolvimentista-nacionalista, a mais importante expressão do pensamento econômico brasileiro no período 1930-64. Foi sempre uma ativa participante do debate, seja como formuladora de políticas econômicas criticadas pelos desenvolvimentistas, seja como formuladora de críticas às proposições destes últimos.

A tradição da ideologia econômica brasileira desde o início do século XIX até os anos 30 foi liberal, como é consenso entre os historiadores. A crise internacional e as transformações econômicas, políticas e sociais que se seguiram solaparam a base real de sua sustentação. Nasceram, a partir daí, diferentes concepções do desenvolvimento brasileiro. Em reação, a ideologia liberal teve de passar, ela mesma, por transformações que viabilizassem sua resistência frente à nova realidade. O neoliberalismo econômico foi resultante desse processo.

Os economistas neoliberais preocupavam-se primordialmente em defender o sistema de mercado, fórmula básica de eficiência econômica. Eram, portanto, primordialmente liberais. O prefixo neo tem um significado muito preciso: representa o fato de que os liberais brasileiros, em sua maioria, passaram a admitir, na nova realidade pós-1930, a necessidade de alguma intervenção estatal saneadora de imperfeições de mercado, as quais, segundo reconheciam, afetavam economias subdesenvolvidas como a brasileira. Esta posição é análoga à dos liberais que fizeram concessões ao keynesianismo, admitindo medidas anticíclicas como forma de recondução de economias desenvolvidas à situação em que, segundo acreditavam, os mecanismos de mercado poderiam voltar a garantir equilíbrio e eficiência.

Três aspectos fundamentais caracterizaram a posição dos economistas da corrente neoliberal no Brasil:

- eram partidários do princípio de redução da intervenção do Estado na economia brasileira;

- manifestavam-se continuamente a favor de políticas de equilíbrio monetário e financeiro, evitando a discussão dos seus efeitos sobre os níveis de renda e emprego;

- não propunham medidas de suporte ao projeto de industrialização e eram freqüentemente contrários a essas medidas.

O principal núcleo de militância intelectual dos economistas neoliberais foi a Fundação Getúlio Vargas (FGV). Pouco depois de sua criação, em 1944, os eco- 
nomistas Eugênio Gudin e Octavio Gouvêa de Bulhões lograram formar uma sólida divisão de pesquisas econômicas que, em 1950, ganhou o nome de Instituto Brasileiro de Economia (IBRE). A partir de 1948, a equipe passou a editar a Revista Brasileira de Economia, que foi a primeira publicação acadêmica brasileira de bom nível no campo da Economia. Em 1952, a equipe passou a controlar a outra importante revista da FGV, ou seja, a Conjuntura Econômica, que desde sua primeira edição, em 1947, estivera sob a direção de intelectuais de linha desenvolvimentista. O grupo teve também marcada influência sobre o ensino de Economia no país. Gudin e Bulhões introduziram o primeiro programa de curso superior dirigido exclusivamente à Ciência Econômica e foram, na Universidade do Brasil (depois UFRJ), os líderes intelectuais da Faculdade de Economia, isoladamente a mais importante do país por muito tempo. Vários outros economistas do grupo Gudin-Bulhões também lecionaram nessa Faculdade.

Neste artigo apresenta-se uma resenha do pensamento econômico do líder intelectual da corrente neoliberal, Eugênio Gudin, que expressou da forma mais acabada a posição básica de sua corrente.

Eugênio Gudin foi o mais importante economista conservador brasileiro do período 1930-64. Engenheiro por formação, converteu-se em economista já em idade madura, mediante esforço autodidático. Foi responsável pelo primeiro trabalho sério de ensino e legitimação da teoria econômica no Brasil, podendo ser considerado o patrono dos economistas brasileiros (1). Foi também o líder teórico da corrente de pensamento neoliberal no país.

\section{O pensamento de Gudin}

Gudin posicionou-se com desenvoltura sobre todas as grandes questões de economia política brasileira, problematizando-as com coerência e vivacidade. A seus textos, escritos quase sempre em linguagem acessível mesmo para leigos em Economia, voltavam-se não apenas os políticos e economistas conservadores em busca de argumentos que norteassem seus posicionamentos, mas também a intelectualidade desenvolvimentista. Esta se via continuamente impelida à obrigação do exercício de crítica às análises de Gudin, não só pela importância prática que tinham essas análises, de ampla divulgação pública, mas também pelo conhecimento da firmeza e coerência da sua linha de argumentação. Diante da segurança com que divulgava os postulados neoliberais, é difícil imaginar que o debate sobre desenvolvimento econômico ficasse mais ou menos balanceado, como ficou, não fosse a riqueza da interpretação antiliberal inspirada em Prebisch e nos textos da CEPAL de um modo geral.

Gudin foi um típico economista neoliberal, levado a reinterpretar os grandes enunciados das teorias liberais à luz da problemática econômica revelada pela 
depressão cíclica do período entre as duas Grandes Guerras. Fez um esforço de recuperação do princípio fundamental da economia clássica, isto é, uma defesa qualificada do princípio da não-intervenção estatal na economia, através de uma rica problematização analítica de sua aplicação ao caso dos países subdesenvolvidos. Na sua busca, identificou-se profundamente com o pensamento de Jacob Viner e Gott Fried Haberler, dois dos maiores livre-cambistas de sua época, com os quais nutriu inclusive amizade pessoal.

Como se sabe, os livros desses dois economistas são considerados grandes obras de reavaliação e sustentação do princípio clássico da divisão internacional do trabalho. Seus autores procuram preservá-lo, levando em conta a existência de ciclos econômicos e procedendo a uma discussão sistemática da validade do livrecambismo frente a argumentos protecionistas. Gudin encontrou nessas obras o suporte teórico ideal para seu posicionamento em relação à questão central do debate desenvolvimentista dos anos 40 e 50 - isto é, das políticas econômicas de apoio à industrialização. Mas não era um mero repetidor de argumentos. Longe disso, foi sobretudo nessa área analítica que exibiu sua criatividade. Viner e Haberler escreveram com a atenção voltada essencialmente para as economias desenvolvidas, a não ser em fase mais adiantada, já no início dos anos 50, e inclusive sob o estímulo do próprio Gudin (2). Este, por sua vez, teve a originalidade de repensar o livre-cambismo pela ótica especial dos países subdesenvolvidos. Dificilmente outro economista liberal de países atrasados terá feito, em plena década de 40, um esforço tão consistente como o de Gudin para readaptar os postulados clássicos às economias subdesenvolvidas, ou "reflexas", se quisermos empregar o termo cunhado pelo próprio autor.

O resultado desse esforço intelectual foi que, ao invés de uma recusa pura e simples da idéia da industrialização brasileira, em nome de um livre-cambismo puro e ultrapassado, Gudin tinha a respeito uma visão sofisticada e atualizada. Roberto Campos afirmou certa vez que o estruturalismo é uma espécie de contraponto intelectual do keynesianismo na América Latina. Talvez não seja exagero afirmar, analogamente, que Gudin proporcionou uma espécie de contraponto intelectual do neoliberalismo na América Latina, ou, mais especificamente, no Brasil. Sistematizou os argumentos liberais, levando em conta uma série de características específicas das economias subdesenvolvidas, e problematizando o liberalismo como procedimento para sua preservação em economias atrasadas.

A hipótese central de sua argumentação é a da existência de pleno-emprego na economia brasileira. Era este um ponto indispensável à consistência de suas formulações. Tinha Gudin plena consciência disto - e total convicção da existência do pleno-emprego. Poucos são seus textos mais importantes sobre a economia brasileira em que não repetiu enfaticamente a idéia de que a mesma sofre de 
baixa produtividade e de "hiperemprego" - e não, como diziam os desenvolvimentistas, de desemprego.

Esse foi também o argumento que lhe permitiu compatibilizar uma interpretação dos fenômenos monetários que evitou a polêmica teórica keynesianismo versus monetarismo, com uma posição resolutamente antiestruturalista e próxima das políticas ortodoxas preconizadas pelo FMI. Seu livro-texto, Princípios de economia monetária, não é o trabalho de um quantitativista rígido. A hipótese do pleno-emprego tornava-o imune, porém, em sua análise convencional da inflação brasileira, à crítica keynesiana.

Armado de um sistema analítico engenhosamente adaptado para enfrentar as questões da economia política brasileira, Gudin foi o grande adversário teórico dos desenvolvimentistas brasileiros de orientação nacionalista. Um adversário aguerrido, sem dúvida, porque, politicamente, era um liberal e um conservador dos mais fervorosos. Talvez por isso mesmo, sua discussão relativa à questão do planejamento econômico seja algo incompleta se comparada a outras questões essenciais. Predominou nessa questão sua obsessiva oposição política a intervenções do Estado na economia, que considerava corresponderem a perigosas concessões ao socialismo. Daí decorre o tom marcadamente ideológico de alguns dos seus textos.

Procuramos, aqui, fazer uma resenha razoavelmente abrangente da obra do autor. Torna-se imediatamente evidente, logo num primeiro contato com a mesma, que suas idéias estão solidamente sedimentadas num firme alicerce teórico, e que seu raciocínio sobre questões concretas passa freqüentemente por essa elaboração sistemática da aplicabilidade dos seus fundamentos teóricos à análise da realidade. É mesmo parte do seu estilo de professor pioneiro do ensino sistemático de Economia no Brasil fazer, como artifício didático, as pontes necessárias entre a retaguarda teórica e a superfície concreta de suas argumentações aplicadas à economia brasileira.

Nossa resenha reproduz o percurso lógico do pensamento de Gudin: inicialmente, fazemos uma breve apreciação de seus fundamentos teóricos; em seguida, analisamos seu pensamento no que diz respeito à aplicação da teoria econômica aos países subdesenvolvidos.

O grande mestre da corrente neoliberal brasileira possuía uma argumentação teórica consistentemente articulada, com a qual sustentava e enriquecia suas análises da economia brasileira.

\section{Traços característicos da posição teórica}

A fonte básica para detectar essa base teórica é seu livro-texto Princípios de economia monetária, que o próprio autor tratava como uma espécie de manual de 
referências teóricas para suas análises concretas da economia do país. Vale notar, a respeito do livro, que sua estrutura retrata com fidelidade as características do envolvimento de Gudin com a Ciência Econômica. Ele não era o que se convenciona chamar de economista teórico (3). Foi um economista aplicado por excelência. Buscava na teoria econômica o instrumental necessário para entender uma série de questões reais que o inquietavam - como as da inflação, dos ciclos econômicos, do comércio internacional para países subdesenvolvidos, e assim por diante. E fazia-o com o objetivo prático de entender as possibilidades de influenciar essas questões mediante políticas econômicas, e de entender o sentido e o alcance das mesmas.

Não teve, por exemplo, a preocupação de tratar teoricamente os princípios liberais (4), o que se reflete mesmo em seu livro-texto (Gudin, 1952b) (5). Essa sua principal obra acadêmica mantém uma clara inclinação para a orientação da política econômica, que sugere, quando se considera a carreira do autor, uma vasta "declaração de princípios de economia monetária" de um candidato a presidente do Banco Central ou a ministro da Fazenda (6).

Gudin era um liberal convicto, mas atento. Preocupavam-no as deficiências de seus princípios, que ele procurava relativizar visando a sua preservação. $\mathrm{Ou}$ seja, seu raciocínio econômico, por um lado, assentava-se sobre o princípio clássico de que a economia capitalista tenderia a um equilíbrio de máxima eficiência sempre que os mecanismos de mercado pudessem funcionar livremente. Por outro, qualificava extensamente esse postulado central da visão liberal à luz das evidências históricas e dos avanços da teoria econômica. Admitia e discutia, por exemplo, a ocorrência de crises de causas endógenas e de depressões cíclicas. Considerava corretas as idéias de Keynes para entender os períodos de depressão, e foi um dos primeiros a divulgá-las em português, na edição de 1952 de seu livro-texto.

Não só aceitava alguma intervenção do Estado para corrigir as deficiências de funcionamento do sistema econômico em períodos de depressão, como inclusive, bem à moda do ressurgimento do otimismo neoliberal dos anos 50 , evoluiu para a visão de que, mediante políticas econômicas adequadas, pode-se até neutralizar as oscilações cíclicas. Defendia, porém, o princípio da mínima intervenção estatal e a idéia de que, nas épocas de prosperidade, a presença do Estado na economia deve ser evitada ao máximo, porque contrabalança a tendência à eficiência alocativa dos mecanismos do mercado.

A flexibilidade teórica do livro-texto de Gudin contrasta com a cruzada antiintervencionista que o autor praticamente liderou no debate brasileiro. $\mathrm{O}$ contraste existe, mas não implica contradição. Gudin sempre zelou pela coerência de suas idéias. Tratava o caso do Brasil como o de uma situação de permanente pleno-emprego, o que eliminava a necessidade de concessões teóricas do tipo das que fazia na análise de economias maduras. Como veremos mais adiante, mesmo 
no caso do Brasil e das economias subdesenvolvidas em geral, nas quais o autor encontrou uma série de características que o levaram a recomendações de política externa bastante heterodoxas, recomendações essas perfeitamente compatíveis com seu receituário conservador em relação ao eixo central da política econômica.

A hipótese de pleno-emprego permitia-lhe também coerência entre sua flexibilidade teórica no tratamento das questões monetárias e a ortodoxia de suas recomendações de política antiinflacionária para o Brasil. No plano da análise monetária, Gudin não pode ser considerado um monetarista rígido. Seu livro contém afirmações suficientes para demonstrar sua inclinação "não-monetarista" no tratamento das questões monetárias. De início, cabe ressaltar que, da mesma forma como concordava com a crítica keynesiana à lei de Say, Gudin não aceitava os postulados rígidos da versão clássica da teoria quantitativa, isto é, recusava o que se pode chamar de "contrapartida monetária da lei de Say". Fica claro, em seus textos, que considerava complexa a relação entre preços e quantidade de moeda, necessitando a consideração de uma série de variáveis reais (7). E fica explícito, logo no capítulo introdutório do volume II, que considerava fundamental examinar a "integração da teoria monetária na teoria da renda, consumo e investimento" (8).

O livro Princípios de economia monetária tem a falha de não examinar a teoria da inflação. Mas não é difícil identificar a visão do autor a respeito, pois os seus textos aplicados à inflação brasileira contêm diversas passagens em que ele explicita sua interpretação a respeito das causas da inflação. Considerava a inflação um fenômeno revelador de situações próximas à de pleno-emprego. Sua análise repousa sobre a noção de excesso de demanda, enfatizando os aspectos de expansão de crédito e déficits orçamentários públicos. É ainda complementada pela idéia de inflação de custos baseada em elevações de salários.

Seu exame da questão pretendia estar sempre levando em conta a capacidade de resposta do sistema produtivo às pressões da demanda, ou então a questão dos custos produtivos, igualmente situada na esfera real do sistema. Gudin era geralmente chamado de monetarista de dois outros pontos de vista, externos ao eixo central da teoria monetária: primeiro, a expressão aplica-se do ângulo especial da teoria estruturalista; e, segundo, do ângulo da crítica de que, na prática, a política econômica que preconiza é monetarista, porque sua análise de que a economia encontra-se em pleno-emprego e plena capacidade é equivocada, e também porque não leva em conta os efeitos depressivos das políticas estabilizadoras.

Como vemos, a classificação de Gudin como economista conservador requer, quase sempre, cuidadosas qualificações. Nem mesmo a idéia, comum no Brasil, de que ele aderia incondicionalmente às teses do FMI chega a ser perfeitamente correta. Gudin demonstrou, é certo, entusiasmo pelas proposições básicas 
que pautaram as ações desse órgão, conforme o espírito da Conferência de Bretton Woods (a que compareceu como delegado brasileiro), isto é, pela reconquista da conversibilidade e pelo equilíbrio monetário e cambial. Tinha, afinal, plena consciência do significado da falência do sistema do padrão-ouro para o funcionamento de um sistema ideal de livres trocas internacionais e da importância que a vigilância sobre os processos desequilibradores assumia no novo sistema monetário internacional (9).

Mas Gudin não concordava com o órgão num ponto básico de seu receituário de política monetária, ou seja, na proposição de que se deve buscar equilíbrio simultâneo no balanço de pagamentos e no sistema de preços interno. Considerava que as desvalorizações cambiais prejudicam o combate à inflação porque realimentam o processo inflacionário e permitem uma deterioração nos termos de troca, o que agrava o desequilíbrio externo. Gudin entendia, como o FMI, que a causa do próprio desequilíbrio no balanço de pagamentos só poderia ser a inflação, mas não se mostrava disposto a arriscar frustrar a eliminação da raiz desse desequilíbrio derivado, em função de uma mera tentativa de antecipar sua correção (10).

A visão de que a eliminação da inflação conduz ao equilíbrio externo era usada pelo autor, repetidamente, em oposição à tese cepalina do desequilíbrio externo estrutural. Gudin argumentava haver uma tendência inexorável ao equilíbrio externo, por serem sempre interdependentes os valores de exportações e importações. Para ele, uma interferência protecionista, ao conter artificialmente as importações, acaba afetando igualmente as exportações - e a eficiência alocativa -, porque transfere recursos produtivos das atividades exportadoras para as atividades domésticas protegidas e porque gera um superávit provisório no balanço de pagamentos, valorizando a moeda nacional e desestimulando as exportações. A eliminação da inflação, ao invés da introdução de barreiras ao comércio internacional, é que seria a fórmula para se alcançar a posição que, ao mesmo tempo, equilibra as contas externas do país e maximiza a eficiência do sistema econômico.

Segundo o autor, o mecanismo equilibrador ideal seria uma política de câmbio administrado, porque o sistema de câmbio flutuante atrai especulações, gerando instabilidade. Considerava também que, salvo em situações de inflação permanente e em casos especiais como guerras e depressões, existe uma taxa cambial de equilíbrio estável, que pode ser alcançada mediante uma política cambial adequada, na qual as autoridades monetárias fazem simplesmente o papel que, teoricamente, coubera ao mecanismo espontâneo acionado pelo mercado monetário no tempo do padrão-ouro. A taxa de equilíbrio deveria ser encontrada, segundo o autor, mediante minuciosas pesquisas empíricas, centradas, evidentemente, em estimativas das reações dos fluxos de comércio e de capital às variações na taxa de câmbio corrente. 


\section{A análise das economias subdesenvolvidas}

Gudin sempre estudou a Teoria Econômica preocupado com os problemas dos países subdesenvolvidos, especialmente o Brasil. Era, como observamos, um economista não-teórico, cujo recurso à teoria se fazia com vistas à política econômica. Era, em outras palavras, um intelectual engajado nas questões concretas da Economia Política de seu país.

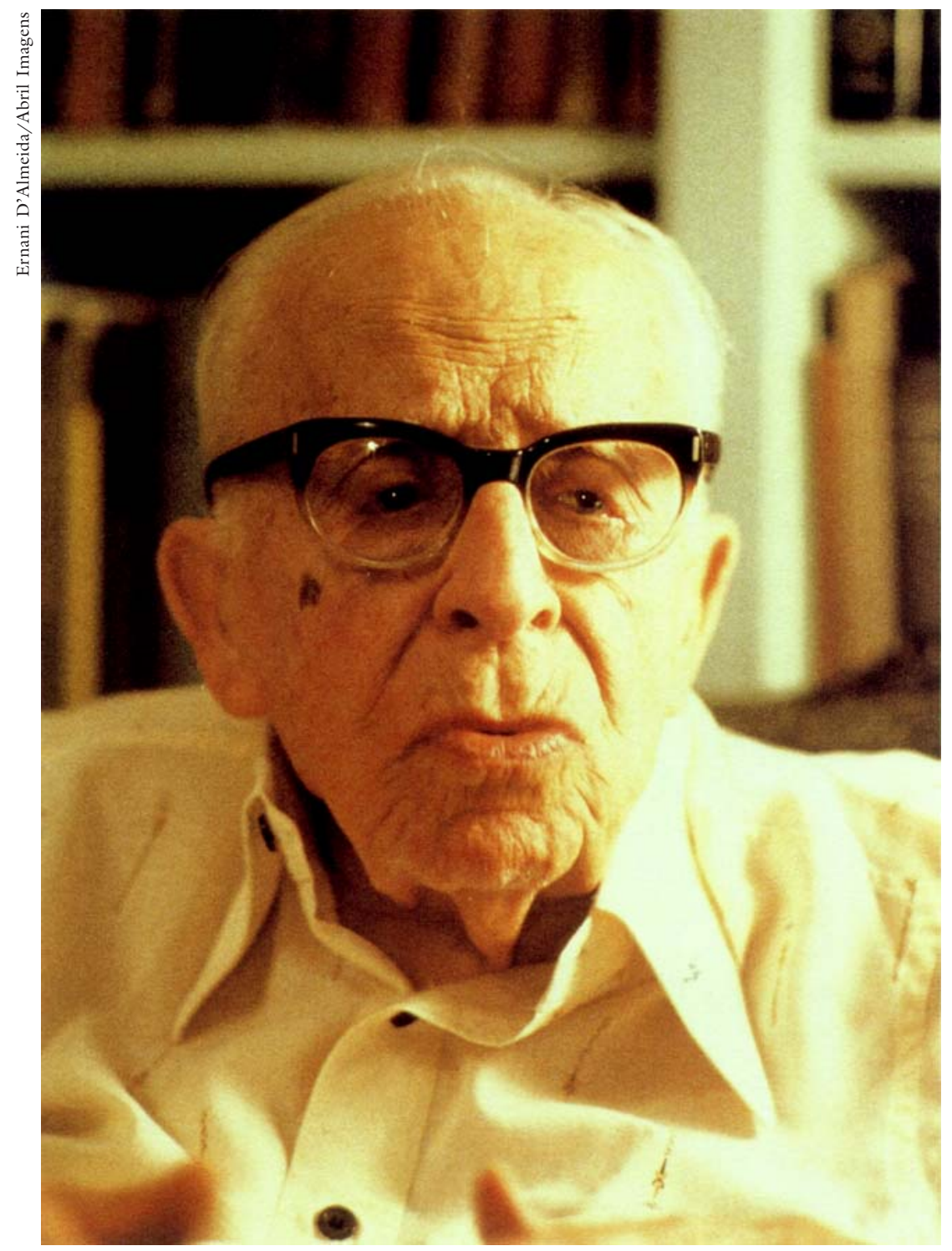

Eugênio Gudin (1886-1986)

Gudin sempre incentivou a discussão sobre problemas do subdesenvolvimento. Por exemplo, como presidente do Instituto de Economia da Fundação Getúlio Vargas, trouxe ao país, nos anos 50, uma série de economistas de renome, 
ligados a essa área de discussão - como Nurske, Singer, Wallich, Kaldor, Viner, entre tantos outros. Como membro assíduo da Associação Econômica Internacional promoveu, no Rio de Janeiro, sua conferência de 1957 sobre o tema do "Desenvolvimento econômico na América Latina".

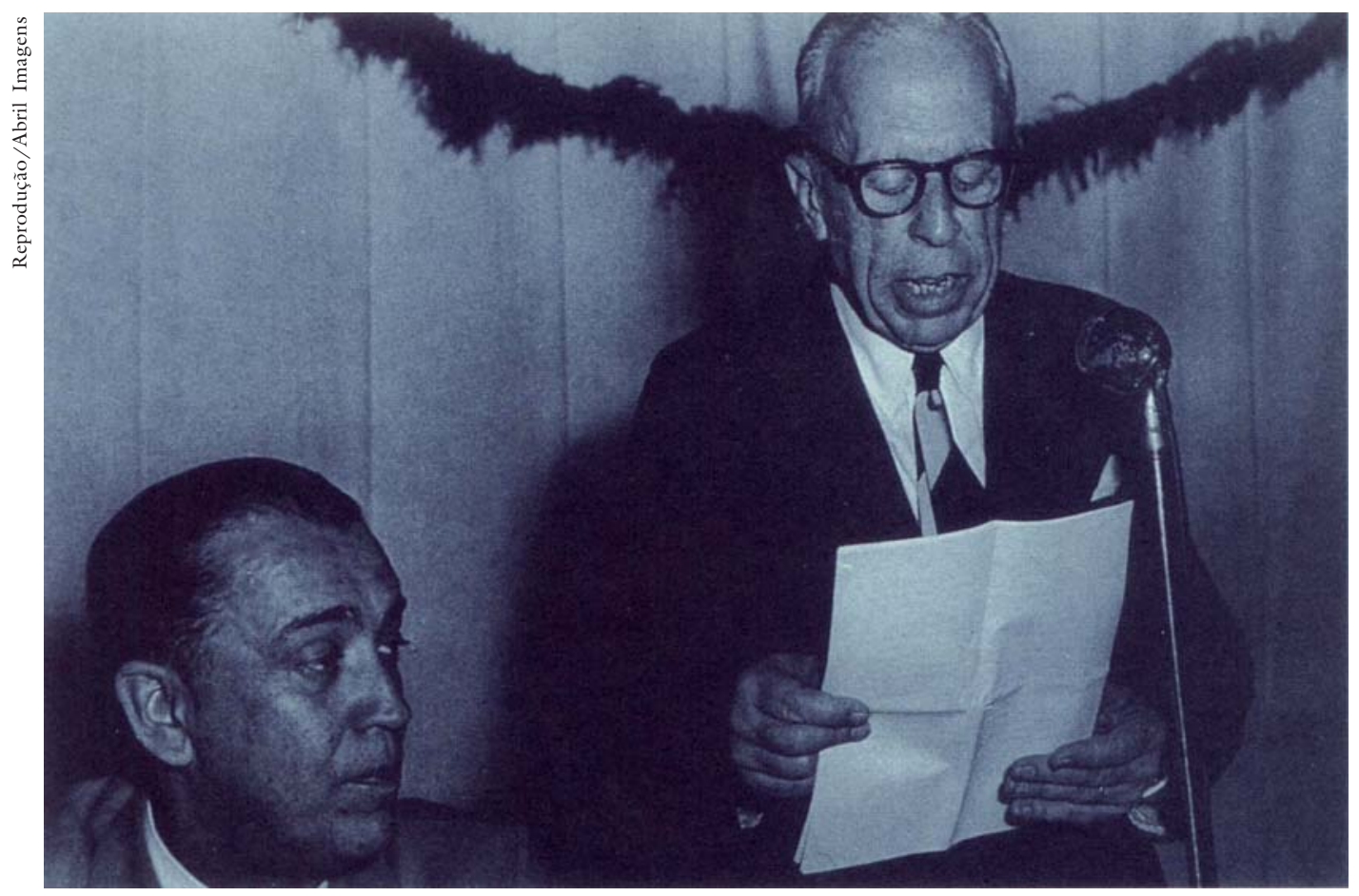

O presidente Juscelino Kubitschek foi um dos ouvintes das conferências do economista Eugênio Gudin

Sua posição a respeito da problemática teórica do subdesenvolvimento vem expressa em um grande número de textos (por exemplo, Gudin, 1952a, 1954a, 1954b, 1956b, 1957a, 1962a). Essencialmente, considerava que a teoria econômica era uma só - a mesma para economias desenvolvidas e atrasadas -, mas pensava que, do ponto de vista da formulação de políticas econômicas, "as diversidades de estrutura são bastante marcadas para que seja preferível tratar de cada caso separadamente" (Gudin, 1952b v. II: 223-224).

Salientava sempre a distinção entre a uniformidade do instrumental teórico e a variedade das análises aplicadas, afirmando, por exemplo, que se justifica inteiramente a organização promovida pelas Nações Unidas de uma Comissão Econômica para a América Latina (CEPAL), para o estudo especial do desenvolvimento econômico de países que, em graus diferentes, podem ser classificados como subdesenvolvidos (Gudin, 1952a: 53). Mas, mesmo assim, observava logo em seguida, que esse tipo de reconhecimento não implica considerar necessário o abandono da teoria econômica existente, acrescentando que "as equações são as mesmas, apenas os parâmetros variam” (Gudin, 1952a: 53). 
O enfoque do autor relativamente ao estudo do subdesenvolvimento foi precisamente o de identificar os "novos parâmetros" e implicações em termos das políticas econômicas de natureza livre-cambista, alterando-as onde necessário. Interessava-lhe, em outras palavras, conhecer as características especiais das economias subdesenvolvidas que exigem políticas econômicas distintas daquelas empregadas nos países desenvolvidos, para que, em última instância, a eficiência da economia de mercado fosse preservada.

Vale citar, ainda do mesmo texto, sua afirmação sobre o que deveria ser estudado: as características da economia dos países subdesenvolvidos, não só em conjunto, como de cada um separadamente, especialmente em relação à natureza da procura e da oferta de seus produtos de comércio internacional e respectivas elasticidades-preço e renda, aos efeitos reflexos vindos do exterior, a seu comportamento cíclico etc e - mais do que tudo - aos meios de promover a formação de capital e a melhoria de sua produtividade agrícola e industrial (Gudin, 1952a: 54).

Sobre essa proposta cabem duas observações. Primeiro, a de que, ao mencionar "os meios de formação do capital e melhoria da produtividade", o autor tinha

\section{... parecia não acreditar na idéia de economias externas globais promovidas por um processo de industrialização ...} em mente os meios convencionais - como atração de capital estrangeiro, formação de mercado de capitais, educação e, sobretudo, obediência aos princípios da economia de mercado. Ex-

cluía o planejamento, era cauteloso quanto à elevação da tributação e parecia não acreditar na idéia de economias externas globais promovidas por um processo de industrialização. Segundo, a de que o estudo das características a que se refere prende-se ao intuito de adaptar os postulados clássicos às especificidades das economias primário-exportadoras. Foi essa a sua intenção quando, ao refutar a idéia de abandono da teoria econômica convencional para análise de economias subdesenvolvidas, ele faz a ressalva de que quando se entende por "escola clássica" o conjunto de princípios que prevaleceram praticamente até a Primeira Guerra Mundial, é claro que ela não se aplica hoje aos países subdesenvolvidos, nem aos próprios países desenvolvidos, sem importantes adaptações (Gudin, 1952a: 53).

Em resumo, sua preocupação analítica fundamental era proceder a essas adaptações. Essa foi talvez a marca teórica mais característica do líder do neoliberalismo econômico brasileiro, uma marca representativa de sua confiança teórica no livre-cambismo. Essa confiança incluía também o ceticismo quanto à riqueza analítica de novos enfoques, como confirma a significativa afirmação que se segue: 
“As 'teorias' do desenvolvimento econômico são, como sabemos, múltiplas e variadas. É o 'desenvolvimento balanceado' de Rosenstein-Rodan e Nurkse, é o 'imbalanceado’ de Hirschman; é o ‘take-off de Rostow; são as fórmulas de Harrod-Domar; é o critério da produtividade marginal social (SPM) de Khan; é o de Galenson \& Leibenstein de maximização, não da renda nacional, mas da poupança, através da taxa de lucros etc. O que se pode dizer da maioria dessas teorias é que há nelas muita imaginação, mas pouca teoria. Ao passo que a teoria do Comércio Internacional aí está há século e meio com seus postulados fundamentais de pé" (Gudin, 1962a: 23).

É interessante notar que, no mesmo texto em que se lê essa afirmação, o autor demonstrou que tinha alguma consciência do problema da insuficiência da teoria do comércio internacional para tratar das questões dinâmicas do desenvolvimento. Restringiu-se, porém, a fazer referência a autores como Viner e Chenery em apoio à afirmação de que acreditava não haver propriamente um conflito entre o princípio das vantagens comparativas e a teoria de crescimento. Acreditava que o princípio pudesse ser aplicado à política de desenvolvimento em combinação com os elementos essenciais da análise do crescimento. Mas não discutia essa intricada e polêmica questão teórica. Não demonstrou, aliás, em sua obra, uma preocupação com o caráter estático dos postulados clássicos, nem um cuidado de reexaminá-los levando em consideração elementos de natureza dinâmica. Sua participação teórica no debate sobre desenvolvimento teve sempre o sentido de reafirmação qualificada dos princípios liberais e, em muito menor grau, de crítica a alguns dos novos enfoques. A dois deles reservou uma certa atenção: à "teoria do crescimento equilibrado" e à tese da deterioração dos termos de troca.

As principais objeções às idéias de big-push contidas na teoria do crescimento equilibrado foram formuladas por Gudin nos seus comentários a um texto apresentado por Nurkse em conferência da Associação Econômica Internacional, no Rio de Janeiro, em 1957. Primeiro a escassez de capital e outros fatores tornariam inviáveis os investimentos simultâneos na escala desejada pela teoria, a menos que se estendesse o período do investimento de forma antieconômica. Segundo, a idéia nuclear da escassez de mercado, contida na teoria, não se sustentava para uma parcela substantiva dos investimentos, ou seja, para substituição de importações, produção para exportação e inversões redutoras de custo. Terceiro, um big-push não teria condições de evitar facilmente uma inclinação à ação governamental, o que seria extremamente prejudicial. Além desses argumentos, Gudin afirmou, num comentário a um texto apresentado por Rosenstein-Rodan à mesma conferência, não acreditar que o problema da indivisibilidade do capital tivesse uma importância que justificasse a estratégia preconizada pelos teóricos do bigpush (Ellis, 1962: 80; 267-269). 
Quanto à tese da deterioração dos termos de troca, de Singer e de seu "velho amigo e brilhante colega" (que é como costumava se referir a Prebisch), a primeira reação de Gudin foi de concordância. Afirmava, relativamente aos países subdesenvolvidos, que "a experiência parece demonstrar uma acentuada tendência para a piora, a longo prazo, da relação de trocas desses países" (Gudin, 1952b v. II: 258). Demonstrou, então, concordar também com a explicação de que a deterioração seria devida ao fato de o aumento da produtividade nos países desenvolvidos ser absorvido por elevações salariais.

Nesse mesmo texto, Gudin faz a ressalva de que a inflação dos países subdesenvolvidos, ao conduzir a depreciações cambiais, contribui para a deterioração. Tais depreciações, em combinação com a abundância da oferta de produtos primários, ocasionam a queda de preços desses produtos na moeda dos países importadores. Em edições posteriores do livro e em outros textos, essa idéia foi a única que persistiu como explicação para a deterioração dos termos de troca. Gudin suprimiu a idéia de tendência e passou a explicar essa deterioração como produto da má gestão da política monetária interna nos países subdesenvolvidos. Em outro trabalho, o autor questionou a validade dos dados apresentados por Prebisch, mencionando outros estudos sobre o assunto (Gudin, 1952a: 55-56). Em textos posteriores, tudo o que se encontra é uma atitude de respeito acadêmico para com a tese, combinado a uma contestação de sua validade.

Tanto o desafio aos postulados liberais que essas duas teses contêm quanto sua legitimidade acadêmica explicam a atenção de Gudin aos debates por elas gerados. Afinal, a tese de big-push pede planejamento, e a de Prebisch-Singer dá suporte a um amplo protecionismo, abrindo caminho a uma intervenção estatal muito superior à que o autor estaria disposto a aceitar. De modo geral, suas análises sobre subdesenvolvimento prendem-se exatamente à delimitação da intervenção governamental na economia de mercado. O sentido é o de preservação dos princípios liberais, levando em consideração os ciclos econômicos e as características especiais das economias primário-exportadoras, que as tornam relativamente instáveis.

A política econômica necessária para apressar o desenvolvimento econômico dos países subdesenvolvidos envolveria, segundo o autor, dois conjuntos de preocupações. Primeiro, dever-se-ia privilegiar a defesa da estabilidade monetária e cambial e garantir o funcionamento dos mecanismos de mercado, a fim de que se pudesse conservar o sistema econômico no caminho da máxima eficiência. Segundo, deveriam ser reconhecidas as características estruturais desse sistema que exigem alguma intervenção governamental, justamente para garantir a estabilidade e a eficiência desejadas. Na primeira edição do volume II do seu livro-texto (Gudin, 1952b), na qual já se incluía um precioso capítulo sobre a "Estabilidade econômica dos países de produção primária”, eram listadas nove características e, em seguida, propostas medidas compensatórias. As nove causas estruturais da instabilidade seriam: 
- inelasticidade, a curto prazo, da produção de lavouras perenes, conjugada à incerteza da produção das lavouras ânuas, vulneráveis às condições atmosféricas (como conseqüência, incapacidade, relativamente às indústrias, de variar a produção de acordo com o mercado);

- inelasticidade da procura de gêneros alimentícios e as consideráveis oscilações de preços a que dá lugar, quando conjugada à inelasticidade da oferta (o autor considerava a procura inelástica tanto com relação ao preço quanto à renda, mas observava que a inelasticidade-renda era baixa relativamente à inelasticidade-preço);

- inelasticidade-preço da procura de matérias-primas nos países industrializados e importância decrescente desses produtos nas atividades industriais modernas, como resultado do avanço tecnológico;

- fortes oscilações cíclicas dos preços de produtos primários, acompanhando as variações de renda dos países consumidores;

- pouca diversidade dos produtos de exportação e, conseqüentemente, vulnerabilidade às oscilações cíclicas;

- vulnerabilidade acirrada pelo fato de que o movimento internacional de capitais agrava, ao invés de atenuar, as oscilações cíclicas;

- piora das relações de troca, como resultado de depreciações cambiais provocadas por inflação e conjugadas à abundância de oferta e inelasticidadepreço da demanda (como observamos anteriormente, na edição de 1952 Gudin admitia também a tese de Singer-Prebisch, depois abandonada);

- forte inelasticidade da procura de importações, que se compõe basicamente de mercadorias essenciais;

- crescimento demográfico acentuado.

Em edições mais recentes, o autor acrescentou uma décima característica:

- "vulnerabilidade à inflação, decorrente da ausência de reserva de meios de produção” (Gudin, 1952b v. II: 239 da edição de 1967).

Um economista cepalino, no início dos anos 50, não abriria mão de tão importante reconhecimento das fragilidades estruturais das economias primário-exportadoras. Reordenaria, talvez, os argumentos, alteraria certas ênfases, confirmaria a tese de Singer-Prebisch e acrescentaria alguns elementos, mas validaria enfaticamente a listagem. Concluiria, provavelmente, com a tese de que o desequilíbrio externo é estrutural e sua solução é a industrialização. $\mathrm{O}$ argumento somar-se-ia, então, ao do desemprego estrutural e ao dos ganhos dinâmicos do processo de industrialização, para defender uma estratégia de planejamento desse processo. 
A posição de Gudin era bem outra. Segundo o autor, seria necessário pôr em prática uma série de medidas compensatórias que atenuassem as oscilações da procura e dos preços dos produtos primários, de forma a alcançar estabilidade monetária e cambial e recuperar a eficiência geral do sistema de livre troca.

Convém lembrar, aliás, que também os economistas da CEPAL se batiam por medidas compensatórias relativas à referida instabilidade. Sob vários aspectos, as propostas que viriam a ser veiculadas pela UNCTAD - criação de Prebisch nos anos 60 - não estavam muito longe do que Gudin tinha em mente quando propôs, como delegado brasileiro em Bretton Woods, uma conferência especial para tratar do assunto (11). Havia, contudo, uma diferença crucial de objetivos: o propósito cepalino era o de atenuar o problema do estrangulamento do balanço de pagamentos, que seria estrutural, de forma a viabilizar o processo de industrialização, ao passo que o de Gudin era o de alcançar a estabilidade cambial e monetária, e proteger a obtenção dos ganhos prometidos pela teoria das vantagens comparativas, ou seja, alcançar a "normalidade" necessária ao hipotético funcionamento eficiente da economia de mercado.

O autor mencionou "medidas de caráter preventivo" e "medidas de caráter estrutural" para compensar as fraquezas estruturais. $\mathrm{O}$ controle sobre preços e sobre a produção de produtos primários foi incluído entre as medidas compensatórias preventivas. Gudin as chamou de compensações por mercadorias (formação de estoques reguladores), em contraposição às compensações de caráter monetário, que consistiriam, basicamente, em:

- conter o impacto inflacionista nas fases de prosperidade, absorvendo, por exemplo, uma parcela das receitas de exportação mediante impostos ou congelando-as sob a forma de saldos bloqueados ou certificados intransferíveis;

- liberar esses fundos nas fases de depressão, como medida anticíclica.

O inconveniente de desestimular a produção nas fases de alta de preços e incentivá-la nas fases de baixa deveria ser evitado via estoques de compensação. Explicava o autor haver evidente analogia entre a compensação monetária e a compensação por mercadorias, a primeira, com o propósito de suavizar os efeitos das oscilações dos preços mundiais sobre a economia do país, e, a segunda, de amortecer as próprias oscilações de preços (Gudin, 1952b v. II: 264).

Quanto às "medidas de caráter estrutural”, o autor mencionava o aperfeiçoamento de um sistema financeiro nacional e a diversificação da produção e da exportação. No contexto dessa discussão sobre a necessidade de diversificar a estrutura produtiva, de forma a reduzir a vulnerabilidade das economias subdesenvolvidas, aparece uma de suas mais claras declarações de princípio a respeito da questão da industrialização: 
“Outra medida de reforço estrutural da economia dos países de produção primária é a de uma gradativa industrialização, para diversificar a economia e escapar em parte dos percalços cíclicos. A industrialização per se não assegura de forma alguma um aumento da renda per capita; muita industrialização tem sido mal orientada ou inspirada em objetivos não econômicos. Mas, se a industrialização se processa com mão-de-obra que se tornou supérflua no setor agrícola, por melhoria de sua produtividade técnica, e se ela dispõe da capacidade técnica e administrativa necessária para uma produção eficiente, não há dúvida de que isso representa um excelente elemento de reforço estrutural da economia" (Gudin, 1952b v. II: 240).

Essa questão de relação entre desemprego e industrialização sempre recebeu alguma atenção da parte de Gudin. Pensador neoliberal coerente e consistente, ele reconhecia que "o princípio das vantagens comparativas só começa a funcionar depois que o pleno-emprego é atingido" (Gudin, 1963b: 25). Não considerava que as oscilações cíclicas afetassem gravemente o nível de emprego nos países subdesenvolvidos (Gudin, 1952b v. II: 223), mas reconhecia o problema da dificuldade de expandir indefinidamente o emprego em atividades de exportação. Por outro lado, mostrava-se sempre bastante reticente quanto às conclusões que se poderiam tirar a esse respeito. Vale a pena transcrever em toda sua extensão a passagem em que o autor melhor equacionou sua visão dessa problemática:

"Se é verdade que as economias predominantemente primárias padecem das duas inferioridades congênitas que apontamos - a da dificuldade de expansão do volume de suas exportações, proporcionalmente ao aumento da renda real dos países compradores (lei de Engel), e da instabilidade cíclica dos preços de seus produtos, com as sérias repercussões de toda ordem que isso acarreta -, é natural que os países subdesenvolvidos tenham procurado evoluir para um tipo de economia mais favorável e menos instável, tratando de industrializar-se."

"Há um caso em que a política da industrialização se justifica integralmente: é o dos países superpovoados, em que se verifica, positivamente, a existência de desemprego disfarçado, como na Índia e no Egito. Nesse caso, o valor da mão-de-obra pode quase ser desprezado no cálculo das vantagens comparativas. Exagerando, dir-se-ia que a mão-de-obra é de graça.”

"Há, de outro lado, o caso oposto, dos países excepcionalmente bem dotados para a produção agrícola, como a Argentina, a Ucrânia ou as planícies do baixo Danúbio. Porque aí as desvantagens congênitas do tipo de economia são largamente superadas pela grande vantagem comparativa da produção agrícola a custos reais muito baixos” (Gudin, 1952a: 64-65). 
Gudin admite aí a validade de dois argumentos favoráveis à industrialização - ou seja, o que se rotula "lei de Engel" e o de "redução da vulnerabilidade às oscilações cíclicas”. Em outros textos fez também referências à idéia de "indústria infante", aceitando a validade de algum protecionismo, e também à idéia de que "a indústria tem sobre a agricultura a vantagem de admitir melhor o transplante das técnicas desenvolvidas nas economias avançadas". No entanto, seu reconhecimento de argumentos a favor da industrialização sempre acompanhou textos, de sentido geral conservador, nos quais predominavam as recomendações de que se evitassem transgressões prematuras às regras de mercado.

Esses quatro argumentos têm, de fato, pouca força na visão global do autor. Mesmo sua preocupação com a vulnerabilidade ao ciclo econômico, maior talvez nos anos 40, decresceria com a prosperidade posterior; sua análise sobre as exportações brasileiras acentuava essencialmente os erros de política econômica, e muito pouco o problema da insuficiência da demanda internacional; e, mais importante em seu pensamento do que as idéias de "transplante de técnicas" e "indústria infante", observa-se sua completa omissão quanto à idéia fundamental de elevação da produtividade pela via de economias externas promovidas por um processo de industrialização. Com efeito, Gudin parecia não reconhecer a possibilidade teórica de que o mercado fosse um mau sinalizador para a alocação eficiente de recursos, a não ser, conforme vimos, no caso do comércio internacional, diante das características estruturais das economias subdesenvolvidas. Mesmo assim, a industrialização era admitida, sob certas hipóteses, como medida compensatória, mas não como um processo de conquista dinâmica de maior produtividade para o conjunto do sistema econômico.

O sentido conservador de sua menção aos argumentos pró-industrialização está bem claro na passagem anterior: na Argentina e na Ucrânia não se justificaria uma industrialização. No caso do Brasil, cujos solos não são tão férteis, sua posição era a de que se deveria aguardar que a elevação da produtividade na agricultura liberasse gradativamente a escassa mão-de-obra, para então progredir lentamente em direção à industrialização. A existência de pleno-emprego eliminaria as justificativas de políticas industrializantes imediatas.

\section{Notas}

1 Em 1941, Gudin submeteu ao ministro da Educação, Gustavo Capanema, sua proposta de renovação do Programa dos Cursos de Ciências Econômicas nas universidades brasileiras, elaborado em colaboração com os professores Maurice Byé e Octávio G. de Bulhões. Louvado por grandes mestres de Harvard, em 1944, o projeto foi base do ensino de economia em todo o país. É o seguinte o seu conteúdo, distribuído por um período de quatro anos: 
$1^{\circ}$ ano: Curso Geral de Economia Política; Estrutura das Organizações Econômicas; Geografia Econômica Geral e do Brasil; Matemática Superior; e Trabalhos Práticos;

$2^{\circ}$ ano: Teoria do Valor e da Formação de Preços; Teoria da Moeda e do Crédito; Estatística; História Econômica Geral e do Brasil; e Trabalhos Práticos;

$3^{\circ}$ ano: Teoria da Repartição da Renda Social; Teoria do Comércio e dos Câmbios Internacionais; Métodos Estatísticos e Matemáticos Aplicáveis à Economia; Ciência das Finanças; e Trabalhos Práticos;

$4^{\circ}$ ano: Teoria da Evolução Econômica e Política de Conjuntura; Estudo Comparado dos Regimes Econômicos; Sociologia e Economia; História das Doutrinas Econômicas; e Preparo de Teses.

Ver, sobre a obra de Gudin como professor, o curto, mas expressivo, artigo de Chacel (1979: 27-29).

2 O famoso trabalho de Viner, no qual ele reafirma o princípio das vantagens comparativas e faz recomendações ortodoxas de política econômica a países subdesenvolvidos, foi o texto da conferência que pronunciou no Rio de Janeiro a convite de Gudin (ver Viner, 1951a e 1952).

3 Ocasionalmente, porém, ele chegou a tentar algumas incursões no terreno teórico (ver, a respeito, Vieira, 1979).

4 Por exemplo, não se encontra entre seus escritos uma discussão das teorias das vantagens comparativas. A respeito do comércio internacional, ele faz apenas tímidas incursões, atendo-se às questões relativas ao balanço de pagamentos e às taxas de câmbio.

5 Uma prova de que o autor optou por não se aprofundar na teoria do comércio internacional pode ser encontrada no exame de distintas edições do primeiro volume do seu livro-texto. Há, nas primeiras edições, quatro capítulos sobre balanço de pagamentos e taxa de câmbio, enfeixados sob o título algo equivocado de "Teoria dos câmbios internacionais". Gudin resolveu excluí-los das edições posteriores, provavelmente porque concluiu que dera um tratamento incompleto ao tema e que, além do mais, os capítulos estavam inteiramente deslocados no contexto da obra.

6 O primeiro volume, cuja edição inicial data de 1943, versa sobre "moeda e bancos" e inclui uma descrição sobre os bancos centrais da Inglaterra, França e Estados Unidos, bem como comentários sobre os sistemas bancários latino-americanos e brasileiro. $\mathrm{O}$ segundo volume, editado em 1952, já se inicia por uma passagem explícita da teoria monetária à política monetária, via taxas de juros (Livro I: "Elementos básicos de política monetária"). Seguem-se capítulos de "Introdução à política econômica", versando sobre controle inflacionário, ciclos, a teoria do multiplicador e do acelerador e a teoria do emprego (Livro II). O desfecho da obra dá-se com o tema "Política monetária" propriamente dito. O autor examina então a questão da estabilidade econômica e a política monetária e fiscal nos países industrializados, bem como a questão da "Estabilidade econômica nos países de produção primária" (Livro III). 
7 Gudin não examinou, porém, a polêmica teórica que se estabeleceu no após-Guerra a respeito da validade da teoria quantitativa clássica, centrada na complexa questão da variabilidade e previsibilidade da velocidade de circulação da moeda. Sua exposição sobre teoria monetária restringiu-se basicamente a uma resenha das diversas versões da equação de trocas (Fisher, real balance approach e income approach). Também não se preocupou em mostrar o caráter especialmente engajado que o debate sobre a teoria monetária tem em relação à política monetária - isto é, em examinar de que maneira as discussões de caráter teórico tinham importância para as posições assumidas no campo das políticas monetárias.

8 Gudin dá, nesse capítulo, grande destaque a Wicksell, demonstrando considerar a tese do "processo cumulativo" uma notável contribuição. Ressalta, a respeito, a virtude de ter Wicksell mostrado a possibilidade teórica do desequilíbrio entre poupança e investimento por influência da moeda e das taxas de juros. Discute, em seguida, a importância relativa das taxas de juros sobre os investimentos (nesse ponto, porém, a discussão torna-se insuficiente para o entendimento do significado da moeda e dos juros na análise keynesiana do equilíbrio em situações depressivas, porque não examina convenientemente a idéia da preferência pela liquidez, seu papel no corpo teórico keynesiano e suas implicações para a formulação da recuperação econômica).

9 Observe-se que Gudin era um ferrenho opositor do binômio padrão ouro-deflação. Em seu livro-texto, por exemplo, qualifica de "tiro de misericórdia no padrão ouro" o clássico artigo de Joan Robinson no qual este argumenta que o processo de ajustamento do balanço de pagamentos de uma economia regida pelo sistema do padrão ouro dá-se pela via de retração das atividades e do desemprego, e não pelo mecanismo de preços, como supõe a teoria que suporta o sistema. A discussão de Gudin a esse respeito estava claramente marcada pela desastrosa tentativa inglesa dos anos 20 no sentido de restabelecer o valor da libra no nível de antes da guerra. Sobre o assunto, Gudin (1952b, v. II: 118) afirma que: "A deflação a que foi preciso recorrer para restabelecer, em 1925, e manter, por aí em diante, a libra esterlina em sua paridade ouro de antes da guerra deu origem aos grandes sofrimentos da economia inglesa durante esse decênio, com a queda das exportações, a paralisação parcial do parque industrial e as cifras alarmantes de desemprego". É possível, também, que a preocupação teórica do autor a respeito da questão tenha-se iniciado com o trauma nacional causado em 1928 pela política deflacionista de Washington Luís, orientada pelos princípios do sistema do padrão ouro.

10 A propósito da questão da causa do desequilíbrio externo, Gudin apresenta, nas primeiras edições do volume I de seu livro-texto, com destaque, uma argumentação em oposição à "teoria do balanço de pagamentos" com base na teoria da "paridade do poder de compra", de Cassel, ambas empregadas na Alemanha na época da Primeira Grande Guerra. A teoria de Cassel é usada para sustentar duas proposições complementares: primeiro, para inverter a causalidade suposta na "teoria do balanço de pagamentos" e, segundo, para argumentar que, salvo em situações excepcionais, como as de guerras ou depressões cíclicas, o desequilíbrio permanente das contas externas de um país só pode ser causado pela inflação.

11 Veja-se um relato de Roberto Campos (também presente em Bretton Woods) sobre o episódio em FGV (1979: 123-129). 


\section{Referências bibliográficas}

BIELSCHOWSKY, Ricardo. Pensamento econômico brasileiro, o ciclo ideológico do desenvolvimento, $4^{\mathrm{a}}$ ed. Rio de Janeiro, Contraponto, 2000.

CHACEL, J.M. Eugênio Gudin, o professor. In: Eugênio Gudin visto por seus contempoorâneos. Rio de Janeiro, FGV, 1979.

ELLIS, H.S. (ed.). Economic development for Latin America Londres, McMillan, 1962.

FUNDAÇÃO GETÚLIO VARGAS. Eugênio Gudin visto por seus contemporâneos. Rio de Janeiro, FGV, 1979.

GUDIN, Eugenio. O caso das nações subdesenvolvidas. Revista Brasileira de Economia, Rio de Janeiro, v. 6, n. 3, p. 47-78, set. 1952a.

Princípios de economia monetária. Rio de Janeiro, Agir, 1952b.

. Produtividade. Revista Brasileira de Economia, Rio de Janeiro, v. 8, n. 3, p. 9-70, set. 1954a.

Salário mínimo. Digesto Econômico, São Paulo, ago./dez. 1954b.

. Tarifa. Carta Mensal, Rio de Janeiro, Confederação Nacional do Comércio, n. 8, p. 3-12, ago. 1956b.

Orientação e programação do desenvolvimento econômico. Digesto Econômico, São Paulo, n.134, p. 13-27 mar./abr. 1957a.

- Comércio internacional num mundo em desenvolvimento. Digesto Econômico, São Paulo, v. 19, n. 164, p. 17-28, mar./abr. 1962a.

O problema de equilíbrio monetário internacional e as tendências atuais do Fundo Monetário. Digesto Econômico, São Paulo, maio 1963b.

GUDIN, E.\& KINGSTON, J. A taxa de equilíbrio do cruzeiro. Revista Brasileira de Economia, Rio de Janeiro, v. 3, n. 4, p. 7-36, dez. 1949.

VIEIRA, J.M.G. Eugênio Gudin: três contribuições à teoria econômica. In: Eugênio Gudin visto por seus contempoorâneos. Rio de Janeiro, FGV, 1979.

VINER, J. Conferências do professor Jacob Viner. Revista Brasileira de Economia. Rio de Janeiro, v. 5, n. 2, p. 7-225, jan. 195la.

Press, 1952.

International trade and economic development. Glencoe, Ill., Free

RESUMO - NESTE ARTIGO analisa-se o pensamento de Eugênio Gudin, o mais importante eco-nomista conservador brasileiro durante o período que se pode denominar de "ciclo ideológico do desenvolvimentismo". Inicia-se com uma caracterização geral da obra do 
autor no período 1930-64, e com um breve balanço de sua posição teórica. Em seguida, abordam-se suas interpretações sobre as economias subdesenvolvidas, para logo passar a sua visão sobre a economia brasileira. Nesse terreno, trata de suas análises dos temas de econonomia política mais intensamente debatidos naquela fase de instalação da moderna economia industrial brasileira: desenvolvimento e industrialização; protecionismo e planejamento; controle e financiamento dos investimentos (empreendimentos estatais, tributação, sistema financeiro e capital estrangeiro); questões monetárias: inflação e balanço de pagamentos; e questões distributivas: salários, distribuição de renda e reforma agrária.

ABSTRACT - THIS IS AN analysis of the thought of Eugênio Gudin, the most important Brazilian conservative economist within the period which can be termed "developmentalism ideological cycle". First, a general description of the author's writings from 1930 to 1964 is given along with a brief evaluation of his theoretical position. Second, his interpretations of the underdeveloped economies are shown only to go on to his vision of Brazilian economy. Third, the article deals with Gudin's analyses of the political economy issues most intensely debated during the period when modern Brazilian industrial economy was established: protectionism and planning; investment control and financing (government-owned enterprises, taxation, financing system and foreign capital); monetary issues: inflation and balance of payments; distributive issues: salaries, income distribution and land reform.

Ricardo Bielschowsky é professor do Instituto de Economia da Universidade Federal do Rio de Janeiro (IE-UFRJ), e economista da CEPAL.

Este artigo é uma versão resumida e ligeiramente modificada de parte do capítulo 4 do livro Pensamento econômico brasileiro - o ciclo ideológico do desenvolvimentismo (Rio de Janeiro, Contraponto, 2000, $4^{\text {a }}$ ed.) 